\title{
Educação em tempos de pandemia: dificuldades e oportunidades para os professores de ciências e matemática da educação básica na rede pública do Rio Grande do Sul
}

\author{
Education in times of pandemic: challenges and opportunities for \\ Science and Math teachers of elementary education of the public school \\ system in Rio Grande do Sul
}

\author{
Jeronimo Becker Flores (jeronimobecker@gmail.com) \\ Centro Universitário UNIFTEC
}

\author{
Valderez Marina do Rosário Lima (valderez.lima@pucrs.br) \\ Pontifícia Universidade Católica do Rio Grande do Sul
}

\begin{abstract}
Resumo: Este artigo versa sobre uma situação particular ocorrida no ano de 2020: o ensino remoto emergencial desenvolvido em função da pandemia da COVID-19. Objetivou-se compreender as dificuldades e oportunidades emergentes desse cenário para os professores de Ciências e Matemática, no contexto do Ensino Fundamental, na rede pública estadual do Rio Grande do Sul. Em busca de compreensões para essa temática, realizou-se uma pesquisa do tipo estudo de caso, com abordagem qualitativa, cujo corpus foi analisado por meio de Análise Textual Discursiva (ATD). Resultados apontam como principais dificuldades a falta de fluência digital dos professores e o fato de eles não receberem o devido amparo e apoio. Também se percebe a baixa adesão dos estudantes às propostas. Como oportunidades, observou-se que os docentes adotaram práticas alternativas e efetuaram movimentos de incursões na cultura digital. Futuramente, este trabalho poderá ter continuidade, trazendo, assim, compreensões mais ampliadas em relação a essa conjuntura.
\end{abstract}

Palavras-chave: Ensino remoto; Ensino na pandemia; Ensino de Ciências e Matemática.

Abstract: This paper aims discussing a unique situation which came about in the year of 2020: the emergency need for e-learning which resulted from the COVID-19 pandemic. Its objectives are: understanding both the difficulties and emerging opportunities of this scenery for elementary school teachers of Science and Math of public schools of the State of Rio Grande do Sul. In order to understand this topic, a case study of qualitative approach has been done. To analyze the corpus, a Discursive Textual Analysis was used. The results point out that the biggest difficulties were the lack of digital fluency from the teachers and the concurrent lack of support and aid. Also, there was a low level of students' adherence to the proposals. In regards to the opportunities, it has been observed that the faculty have adopted alternative practices and have taken initiative to introduce themselves into the digital culture. In the future, this paper may have continuity, therefore, bringing about further understanding.

Keywords: E-learning; Teaching during the pandemic; Science and Math teaching.

Recebido em: 18/01/2021

Aceito em: 24/02/2021 


\section{INTRODUÇÃO}

No ano de 2020, a pandemia mundial do Corona vírus levou à adoção de medidas públicas de prevenção, dentre as quais o isolamento social, deslocando o modelo educacional presencial para remoto. A força das circunstâncias compeliu a uma mudança desenvolvida sem a adequada reflexão, formação e preparação, submetendo os professores a adaptações nas suas práticas.

A experiência de um dos autores deste artigo indica a vivência de um período de transição e turbulência, composto por dificuldades e oportunidades para os professores da rede pública estadual de ensino do Rio Grande do Sul. Em busca de compreensões para essa problemática, desenvolveu-se a presente investigação, cujo objetivo é compreender as dificuldades e oportunidades emergentes de um ambiente de ensino remoto para os professores de Ciências e Matemática que atuaram nessa conjuntura.

O norteador da investigação é o problema de pesquisa, assim descrito: quais dificuldades e oportunidades afloram em um cenário de pandemia para os professores de Ciências e Matemática da Educação Básica da rede estadual do Rio Grande do Sul? Para assimilar esse contexto, desenvolveu-se uma pesquisa do tipo estudo de caso, a partir de uma abordagem qualitativa, cujo corpus de análise foi constituído por entrevistas semiestruturadas e analisado sob a perspectiva da Análise Textual Discursiva (ATD).

O texto que segue é composto por uma contextualização relativa ao enredo de Educação no isolamento social, seguido de uma teorização sobre o ensino remoto. Na continuidade, tratam-se dos aspectos metodológicos com as escolhas e o percurso percorrido no decorrer da investigação. Encadeado a isso está o cerne do trabalho: as percepções emergentes do processo investigativo, para, finalmente, apresentar-se as considerações finais, trazidas não como algo finalizado, mas como compreensões para futuras ampliações e debates.

Quiçá, em um momento futuro, procurar-se-ão esses docentes com o fim de identificar quais ações adotadas nesse novo quadro incorporaram-se de maneira efetiva nas práticas docentes cotidianas, representando, assim, mudanças nas formas com que as aulas são executadas e concebidas. 


\section{O CONTEXTO DA PESQUISA}

Em 2020, a população mundial viveu um ano atípico em termos sociais, culturais e pedagógicos. Um vírus desconhecido, de alto contágio e letal, compeliu-nos a mudanças comportamentais, atingindo de maneira significativa a Educação, com o rompimento de modelos educacionais conhecidos até então, e urgindo a necessidade de novas práticas.

Medidas de distanciamento social foram adotadas com o propósito de reduzir o contágio, e os educandários logo foram entendidos como possíveis vetores de contaminação. Saraiva, Traversini e Lockmann (2020) lembram que a suspensão das atividades escolares na rede estadual do Rio Grande do Sul ocorreu a partir de 19 de março, com um decreto do governador publicado em uma rede social. Naquele momento, a previsão inicial de retorno era o dia primeiro de abril do ano corrente, cuja efetivação não foi possível, pois ainda não havia condições sanitárias para tal.

A partir disso, a ausência de norteadores públicos e a própria incerteza levaram os docentes a improvisarem e adaptarem as suas práticas, de modo que os estudantes não ficassem totalmente desassistidos. Ao contrário de outros setores, tais como a indústria e o comércio, havia o consenso de que as aulas não poderiam parar, mesmo que o funcionamento não tivesse as condições ideais, com o fim de evitar-se um dano maior (SARAIVA; TRAVERSINI; LOCKMANN, 2020).

Saraiva, Traversini e Lockmann (2020) enfatizam que, no Rio Grande do Sul, a rede estadual, inicialmente, adotou as chamadas "atividades domiciliares", também chamadas de "aulas programadas", práticas caracterizadas essencialmente pelo acesso ao conteúdo. Diversos mecanismos foram empregados, alguns analógicos, outros digitais. Enquanto alguns professores preferiram deixar materiais impressos na escola ou empregar o livro didático, outros aventuravam-se usando redes sociais e plataformas digitais como possíveis substitutos para a sua aula presencial. Assim: "A escola e os professores pensam e planejam determinadas atividades e entregam tais atividades à família que fica responsável pela sua execução (SARAIVA; TRAVERSINI; LOCKMANN, 2020). Uma espécie de "pronta-entrega" de conteúdos, sem um pensar sobre a pedagogia subjacente ao processo ou sobre os possíveis impactos dessas práticas.

Recebido em: 18/01/2021

Aceito em: 24/02/2021 
Edição Especial: I SSAPEC - Simpósio Sul-Americano de Pesquisa em Ensino de Ciências ISSN: 2595- $4520 \quad$ Vol. 4, n. 3. 2021

Segundo as informações oficiais do Governo do Estado $^{1}$, a partir de primeiro de junho, implementou-se o "Ensino Remoto", com o emprego do Google Classroom², um sistema de gerenciamento de conteúdo desenvolvido pela Google com finalidades educacionais. Ocorreu, enfim, uma padronização para os mais de quarenta mil professores da rede estadual. A partir dessa data, as práticas pedagógicas, bem como a disponibilização e entrega de materiais, deveriam ocorrer, preferencialmente, com o uso dessa plataforma.

Em 22 de junho, mais de três meses após o início do ensino domiciliar, houve a disponibilização de uma sala de aula virtual para a capacitação dos professores, com o nome de "letramento digital". Junto a algumas jornadas pedagógicas isoladas, foi o único movimento visando à formação docente observado no decorrer do período de isolamento social produzido em função da COVID-19.

A partir desse momento, as aulas passaram a ocorrer de forma virtual, no entanto, de acordo com Maia e Matar (2007), a virtualidade não é condição suficiente para a caracterização da Educação a Distância (EAD). Não sendo um modelo presencial e não sendo um modelo de EAD, o que os professores estavam fazendo? Essa modalidade foi denominada de ensino remoto, cujos pressupostos definem-se na sequência.

\section{ENSINO REMOTO}

O ensino dito presencial é aquele no qual professores e estudantes encontram-se fisicamente no mesmo espaço físico e geográfico, sendo entendido como a modalidade mais convencional de ensino.

A Educação a Distância, cujo nome sugere um distanciamento físico, pressupõe uma presença digital virtual, a partir das tecnologias digitais e das práticas docentes voltadas à interatividade. Os pressupostos básicos são a flexibilização do tempo e do espaço, bem como as relações sociais entre os pares, estabelecida a partir do uso recursos tecnológicos (MAIA; MATTAR, 2007). Para Moreira e Schlemmer (2020, p. 13): “A Educação a Distância é a interação constante entre os sujeitos as tecnologias e a

\footnotetext{
${ }^{1}$ Maiores informações em https://escola.rs.gov.br/aulas-remotas.

${ }^{2} \mathrm{https} / / /$ classroom.google.com

Recebido em: 18/01/2021

Aceito em: 24/02/2021
} 
Edição Especial: I SSAPEC - Simpósio Sul-Americano de Pesquisa em Ensino de Ciências

ISSN: 2595- $4520 \quad$ Vol. 4, n. 3. 2021

informação e não havia razão para que a EAD imitasse o que poderia ser realizado em sala de aula presencial". Os autores apontam para as distinções da modalidade e indicam a aprendizagem colaborativa, a autonomia discente e a popularização do conhecimento como norteadores do fazer pedagógico na EAD.

Já o ensino remoto parece ser algo entre esses dois polos. Se por um lado não é um modelo presencial, por não contar com a presença física; por outro, também não é uma EAD por, de certa forma, carecer de presença virtual. Esse argumento é reforçado por Moreira e Schlemmer (2020, p. 8), entendendo como uma: "modalidade de ensino ou aula que pressupõe o distanciamento geográfico de professores e estudantes e vem sendo adotada nos diferentes níveis de ensino, por instituições educacionais no mundo todo, em função das restrições impostas pelo COVID-19 [...]”.

Para os autores, o ensino remoto foi composto pela transposição da sala de aula convencional para o contexto digital, com o foco centrado na disposição do conteúdo, seguindo a maioria dos pressupostos já conhecidos como, por exemplo, a transmissão de informações e a centralidade do professor no processo. Mesmo com o afastamento geográfico, o modelo remoto entende a necessidade de encontros síncronos, com uso de videoconferências ou gravações nas quais o professor expõe o conteúdo.

Esse ensino emergencial, dado à força das circunstâncias, não forneceu uma educação online de qualidade, procurando apenas oportunizar um acesso rápido e emergencial à matéria. É, portanto, passível de fragilidades, pois é um modelo educacional concebido na emergência, estabelecido sem a reflexão necessária. Cury (2020) enfatiza que a maior parte dos professores não se sente preparada para lecionar nesse contexto, pois não recebeu qualquer formação ou apoio, precisando, de certa forma, reinventar-se.

Essa reinvenção do docente e da docência é referida por Moreira, Henriques e Barros (2020, p. 354):

A virtualização dos sistemas educativos a que neste momento estamos sendo obrigados a efetuar pressupõe a alteração dos seus modelos e práticas e "obriga" o professor a assumir novos papéis, comunicando de formas com as quais não estava habituado.

O uso de recursos tecnológicos digitais, a gestão da sala de aula em uma conjuntura nova, a produção de conteúdos midiáticos fomentou a necessidade de um 
professor completamente alternativo, exigindo e produzindo uma verdadeira reinvenção da docência.

Dentre os elementos presentes nesse reinventar de práticas esteve o uso dos recursos tecnológicos digitais e o ensino e aprendizagem nesse ambiente, trazendo novamente à tona uma questão há tempos problematizada por distintos pesquisadores: a inclusão da escola na cultura digital.

Especialmente a partir dos anos 2000, ocorreram movimentos de inserção de recursos tecnológicos digitais no cotidiano da escola. Essas iniciativas focaram quase exclusivamente no aparelhamento das escolas, sem promover de maneira suficiente a formação docente e o desenvolvimento de concepções de uso passíveis de fomentarem a construção do conhecimento (PESCADOR; FLORES, 2013). Para Flores e Pescador (2013), o insucesso dessas ações pode ser explicado pela falta de continuidade, foco quase que exclusivo no aparelhamento tecnológico e formação docente insuficiente.

Emerge um questionamento: é suficiente a disponibilização de recursos tecnológicos digitais para a consolidação de mudanças nas práticas? Morais e Fagundes (2011, p. 99) procuram elucidar esse ponto afirmando: “É preciso que haja uma inclusão da escola na cultura digital, mas para que isso ocorra é necessário que ela passe por uma mudança de paradigma educacional.” Essa mudança não é simples. Para Pescador e Flores (2013), isso passa pelo redimensionamento epistemológico da ação docente frente à tecnologia e à cultura digital. Para essa construção, torna-se necessária a formação docente para essa conjuntura, com movimentos voltados ao pensar sobre como o estudante do século XXI aprende frente à tela.

As dificuldades inerentes ao uso dos recursos tecnológicos digitais vêm sendo problematizadas há tempos. Flores (2013) situa esse quadro sugerindo ações públicas voltadas à promoção do letramento digital de professores. Nessa circunstância, o letramento digital é entendido como o emprego social e competente dos recursos tecnológicos digitais, uma dimensão mais complexa quando comparada à simples utilização da tecnologia digital. Assim, os movimentos de formação docente têm um efeito mais positivo quando se voltam para o desenvolvimento de concepções, e não apenas para a aplicação mecânica e instrumental.

O ensino remoto realizado na rede estadual do Rio Grande do Sul produziu transformações pedagógicas e deslocou o professor da sala de aula presencial para uma Recebido em: 18/01/2021 
Edição Especial: I SSAPEC - Simpósio Sul-Americano de Pesquisa em Ensino de Ciências ISSN: 2595- $4520 \quad$ Vol. 4, n. 3. 2021

sala de aula virtual. Quais foram as dificuldades e oportunidades emergentes desse cenário? No tópico a seguir, apresentam-se os caminhos percorridos na busca por compreensões para esse questionamento.

\section{PROCEDIMENTOS METODOLÓGICOS}

Na busca para entendimentos de um fenômeno subjetivo, como a percepção de professores acerca das dificuldades e oportunidades emergentes de um panorama de mudanças pedagógicas, optou-se por uma perspectiva de pesquisa qualitativa. Na visão de Bogdan e Biklen (1994), nessa abordagem, explora-se a sinuosidade do fenômeno, visto na complexidade, a partir de um forte viés social.

O tipo de pesquisa é o estudo e caso. Na visão de Yin (2010), é crível quando a investigação se volta para fenômenos contemporâneos, como nesta pesquisa, direcionada à análise de um fato atual: a pandemia mundial de COVID-19, fator catalizador de mudanças na forma com que as aulas são concebidas e desenvolvidas. $\mathrm{O}$ autor ainda enfatiza a necessidade da observação do fenômeno no seu contexto natural, sem a manipulação de variáveis. Esta investigação direcionou-se para as percepções de professores da rede pública, em um panorama de ensino remoto, sem a produção de qualquer situação artificial, caracterizando, assim, um estudo de caso.

A busca das compreensões referidas nos objetivos passa pela obtenção de dados para a mineração de compreensões, denominada, a partir de Moraes e Galiazzi (2007), como corpus de pesquisa. Ele foi constituído a partir de entrevistas semiestruturadas, em acordo com as prerrogativas de Flick (2004), compreendendo um planejamento aberto, onde o entrevistado discorre sobre o tema, evitando-se, assim, o engessamento e captando-se uma riqueza maior de detalhes.

Dessa forma, entrevistaram-se quatro professores da rede estadual de ensino do Rio Grande do Sul, sendo dois de Ciências (PC1, PC2) e dois de Matemática (PM1, PM2). Chegou-se até esses sujeitos a partir da convivência de um dos autores deste trabalho e o número de sujeitos abrange a totalidade de professores dessas duas disciplinas de uma escola estadual do Rio Grande do Sul.

As entrevistas foram transcritas e analisadas a partir da perspectiva da Análise Textual Discursiva (ATD), em acordo com as propostas de Moraes e Galiazzi (2007). A 
Edição Especial: I SSAPEC - Simpósio Sul-Americano de Pesquisa em Ensino de Ciências

ISSN: 2595- $4520 \quad$ Vol. 4, n. 3. 2021

ATD propõe-se a dedicar um olhar interpretativo para produções textuais, captando o implícito e o explícito a partir de três ciclos recursivos: unitarização, categorização e comunicação.

No primeiro ciclo, os textos são desmontados na busca pelas suas menores unidades de significados; no segundo, as unidades semelhantes são aproximadas. No terceiro ciclo, o pesquisador procura captar o novo emergente e comunicar as compreensões atingidas em articulação com a teoria considerada e a própria visão de mundo do pesquisador (MORAES; GALIAZZI, 2007).

Nos próximos tópicos são apresentados os movimentos descritivos, interpretativos e analíticos relativos à ATD.

\section{RESULTADOS E DISCUSSÕES}

As práticas pedagógicas desenvolvidas atualmente pelos professores têm sido modificadas em função das restrições de contato físico impostas pela COVID-19, deslocando a sala de aula presencial para um espaço virtual. Desse quadro, surgiu o questionamento relativo às dificuldades e oportunidades encontradas por professores da rede estadual do Rio Grande do Sul.

A análise efetuada propiciou a emergência de duas categorias: uma delas relacionada ao conjunto de dificuldades mencionadas pelos professores e outra relativa às oportunidades percebidas pelos docentes no contexto de exigências impulsionadas pela pandemia. A partir disso, formaram-se subcategorias, de acordo com as similaridades dos discursos.

\subsection{Dificuldades}

A categoria dificuldades contempla a insegurança, a incerteza e os entraves relacionados a esse período de ensino remoto. Ela foi organizada em três subcategorias: dificuldades do professor no uso de recursos e plataformas digitais, falta de apoio da comunidade escolar ao professor e baixa adesão dos alunos às propostas.

Em relação às dificuldades dos professores inerentes ao uso, não se tem nesse aspecto uma discussão nova. Há tempos, autores como Morais e Fagundes (2011), 
Flores (2013), Pescador e Flores (2013), dentre outros que não foram citados neste artigo, situam esse quadro, sugerindo ações públicas orientadas ao fomento do letramento digital de professores a partir da formação de professores, conduzindo ao redimensionamento da epistemologia subjacente às práticas docentes frente às tecnologias digitais.

Apesar do tempo decorrido e de muitos autores terem aderido a essa temática, aparentemente, no cenário de ensino remoto, essa questão mostrou-se ainda mais evidente, como se observa nas seguintes falas: "eu nem sabia mandar um e-mail, então de uma hora para outra precisei trabalhar em uma plataforma que eu nem sabia o que era" (PC1). Na mesma direção, PC2 argumenta: "Precisei aprender tudo na hora, testar para ver se funcionava, foi muito tenso, nunca sabia se ia dar certo" (PC2).

As verbalizações indicam uma profunda desapropriação relativa ao uso das tecnologias digitais. Salienta-se o fato de ambos os professores terem uma longa carreira na rede pública estadual, indicando que as eventuais ações de inclusão digital não alcançaram esses docentes. A expressão "de uma hora para outra" aponta para a necessidade de adaptação e confirma as premissas de Cury (2020), cujos argumentos indicam o despreparo para a docência nessa configuração.

Percebe-se a necessidade de movimentos formativos dirigidos a etapas anteriores ao letramento digital, referidos por Flores (2013), parecendo ser necessário um estágio anterior, promovendo incialmente o uso dos recursos para, na sequência, fomentar-se concepções didáticas e pedagógicas. Quando PC2 indica um processo autônomo de aprendizagem relativo à utilização das tecnologias digitais, confirma os argumentos de Saraiva, Traversini e Lockmann (2020) no que se refere ao despreparo dos docentes e também à falta de apoio: "A docência nos tempos de pandemia é uma docência exausta, ansiosa e preocupada" (SARAIVA; TRAVERSINI; LOCKMANN, 2020).

Cabem distintos questionamentos nesse contexto como, por exemplo: como está a saúde a mental do professor? Esse processo de aprender e testar implica em aumento na carga horária? Quiçá em um momento futuro, serão investidos esforços para compreender essa e outras interrogações ascendentes desse novo ambiente.

As angústias e incertezas também são identificadas nas falas de PM1: "Nos mandaram ficar em casa e dar aula de lá. Ninguém sabia o que fazer, se era para mandar folhinha ou mensagem pelo celular. Depois mandaram usar o Classroom, mas Recebido em: 18/01/2021 
ninguém falou como". A verbalização apresenta indícios da verticalização do processo, em que o professor parece não ser ouvido. A incerteza de quais práticas adotar também emerge do estrato em questão, bem como a falta de um norte para a ação pedagógica. Essas ações foram justificadas como uma decisão sanitária, respondendo a um suposto imperativo de que a Educação não pode parar. Teve-se uma sequência, mas com qual concepção? Com qual resultado? As limitações de um modelo emergencial tornam-se evidentes, mas salienta-se a necessidade de pensar sobre o ensino e a aprendizagem, independentemente do modelo.

Afloraram outras dificuldades, conforme o relato de PM2: "Os pais estão sempre criticando: se tem atividade, se não tem, não importa, parece estar sempre errado" (PM2). Na mesma direção: "Parece que tudo o que a gente faz está errado" (PC1). As falas indicam a pressão sofrida pelos docentes, apontando para a falta de reconhecimento dos esforços empreendidos neste momento. Evidenciam-se as mudanças nas relações de poder referidas por Saraiva, Traversini e Lockmann (2020), com os pais ganhando um novo papel, de maior vigilância e controle das atividades realizadas pelos seus filhos e professores.

A falta de reconhecimento e desvalorização do professor, conforme relatam Tardiff e Lessard (2008), é um problema histórico, não sendo, assim, produto da pandemia da COVID-19. O isolamento social submeteu os professores a novas formas de fazer a docência e estabeleceu distintas relações de poder, evidenciando problemas antigos, mas que há tempos afetam o trabalho docente.

Mesmo com formas e relações distintas desencadeadas a partir de um panorama de ensino remoto, problemáticas antigas seguem recorrentes, como, por exemplo, o baixo envolvimento dos alunos. Esse ponto foi referido por todos os entrevistados. Para isso, foi organizado um quadro, cujas análise e interpretação encontram-se na sequência.

Quadro 1: verbalizações.

\begin{tabular}{|l|l|}
\hline Professor & \multicolumn{1}{c|}{ Verbalização } \\
\hline PC 1 & $\begin{array}{l}\text { "A gente planeja, se organiza e na hora da web conferência aparecem só } \\
\text { dez alunos". }\end{array}$ \\
\hline PC2 & $\begin{array}{l}\text { "Poucos entregam as tarefas, poucos participam das aulas, é difícil, não } \\
\text { sabemos o que fazer" [...]. "XXX fez duas e outras só marcou devolvido" }\end{array}$ \\
\hline
\end{tabular}




\begin{tabular}{|l|l|}
\hline & $\begin{array}{l}\text { (PC2). "YYY marcou 'devolvido' em uma, mas não anexou, as outras tudo } \\
\text { pendente”. }\end{array}$ \\
\hline PM1 & “Tem aluno que ainda não fez nenhuma tarefa. Desde março”. \\
\hline PM2 & “A maioria só chuta. Outros escrevem OK, mas não anexam a tarefa”. \\
\hline
\end{tabular}

Fonte: corpus de pesquisa.

As falas indicam um planejamento docente e propostas efetivadas que não alcançam o engajamento esperado, quem sabe, apontando para uma descrença no ensino remoto. Os professores, conforme indicado por Cury (2020), estão despreparados para contornar essas questões e, de certa forma, não visualizam alternativas para a reversão desse quadro.

A análise da fala de PM1 indica que o aluno referido, por um certo ponto de vista, abandou a escola, indicando o descumprimento de um dos propósitos do ensino remoto, sendo, para Saraiva, Treversini e Lockmann (2020), uma resposta para a sociedade, que acreditava na necessidade de a escola funcionar, independentemente das condições. Para esse e outros tantos estudantes, a escola não funcionou. Santos (2020) situa a existência de um processo de exclusão implícito a esse modelo de ensino, atingindo, normalmente, os grupos menos favorecidos.

As falas de PC2 e PM2 apontam para respostas dadas de forma aleatória nas tarefas propostas. Esses estudantes, de certa forma, apenas cumpriram o protocolo, retornando as tarefas para o seu professor. Esse ponto revela a epistemologia subjacente às aulas: a educação bancária, há tempos problematizada por Freire (1987), com o depósito do professor aguardando um retorno do aluno, normalmente efetuado na forma de avaliações. O corpus evidencia a necessidade de repensar esse padrão, pois não tem atingido seus propósitos, visto que os professores sequer recebem um retorno em relação aos conteúdos.

Como contraponto à discussão proposta nesse tópico, existe uma outra face dessa história: as oportunidades que emergiram desse ambiente, cujas perspectivas serão analisadas na sequência. 


\subsection{Oportunidades - Maneiras de repensar a aula}

Oportunidades são entendidas como maneiras de repensar as aulas convencionais, sendo percebidas a partir de dois aspectos: práticas alternativas e incursão na cultura digital. O primeiro refere-se a mudanças observadas em relação às práticas já conhecidas; o segundo, a movimentos na direção da inclusão da escola na cultura digital, na perspectiva referida por Morais e Fagundes (2011).

Historicamente, as aulas de ciências e matemática têm sido pautadas pela transmissão de informações, repetições e centralidade do professor no processo pedagógico (BECKER, 2019). Práticas alternativas são entendidas como ações que buscam quebrar ou reverter essa lógica. O panorama de isolamento social possibilitou alguns procedimentos nesse sentido.

Observam-se indícios de práticas alternativas nas aulas de ciências: “[...] comecei a utilizar vídeos, tem muito material bom. Também me arrisquei a gravar uns vídeos, vou continuar fazendo isso quando tudo passar" (PC1).

PC1 refere-se à transposição da aula do quadro negro para o cenário digital a partir do uso de materiais prontos e de gravações autorais do professor, indicando que essa prática seguirá incorporada às suas aulas quando houver um retorno ao ensino presencial. Esse redimensionamento das práticas é referido por Moreira, Henriques e Barros $(2020$, p. 352): “os professores se transformaram em youtubers gravando videoaulas e aprenderam a utilizar sistemas de videoconferência, como o Skype, o Google Hangout ou o Zoom e plataformas de aprendizagem [...]”.

A conjuntura de isolamento social produziu e compeliu a mudanças nas formas como os professores organizam suas aulas, com o uso de recursos passíveis de enriquecer os aspectos visuais e possibilitar o acesso à informação em tempos e espaços distintos do proposto pela escola convencional. Quem sabe, uma circunstância mais convencional não produziria essas alterações, pois normalmente existe uma tendência de repetição das práticas já conhecidas e estabelecidas (BECKER, 2019). Ou seja, apesar das dificuldades inerentes ao processo, ocorreram oportunidades relativas às mudanças nas atitudes pedagógicas.

PC2 também traz relatos no mesmo sentido: "Existem muitos museus de ciências naturais on-line, eu não sabia que isso existia" (PC2). PC2 ainda completou, afirmando 
que vai usar menos o livro didático e complementá-lo com materiais disponíveis na web.

$\mathrm{Na}$ fala, percebe-se uma referência ao desconhecimento das possiblidades da conjuntura digital, apontando para a busca de alternativas produzidas pelo ensino remoto, a reinvenção da docência referida por Cury (2020). A saída do livro impresso para a exploração de ambientes de realidade simulada, onde, na visão de França e Soares (2015, p. 4), é possível : "recriar, com o maior grau de fidedignidade possível, a sensação de realidade, de modo que uma pessoa adote esse ambiente e as interações que nele ocorrem como uma realidade circunstancialmente plausível”. A interação, presença virtual e imersão nesse tipo de ambiente podem recriar experiências passíveis de efetivar a mobilização cognitiva, capaz de conduzir à aprendizagem.

Quiçá, sem essa conjuntura, essas mudanças não ocorreriam, e as práticas seguiriam os cursos históricos, calcadas nas práticas costumeiras, mais voltadas à transmissão do que à exploração. Atualmente, existem distintos recursos que possibilitam a visualização, exploração e manipulação. No entanto, salienta-se o fato de não ser o recurso que proporcionará a aprendizagem, mas a ação pedagógica frente a essas possibilidades (FLORES; PESCADOR, 2013).

Nas aulas de matemática, também foram observados movimentos relacionados a práticas alternativas. Historicamente, o ensino de matemática é regrado por práticas verticais, centradas na figura do professor, com mecanização e repetição de procedimentos. Aprender, geralmente, é visto como sinônimo de repetir e praticar (BECKER, 2019). O ensino remoto levou os professores interrogados neste trabalho a adotarem condutas distintas, conforme se relata na sequência.

"Eu passei a usar alguns programas como o Graphmatica para geometria. Também tentei usar o Excel, mas ainda não tenho bem confiança” (PM2). O trecho indica o uso de programas orientados à visualização e à manipulação, possibilidades diminutas em uma aula ministrada apenas como o quadro negro. Tall (2008) indica que o desuso da abordagem geométrica e visual constitui em um vetor de dificuldades de aprendizagens em matemática.

O primeiro programa referido pelo entrevistado apresenta possibilidades para a exploração geométrica, bem como a visualização de conceitos matemáticos e manipulação de sólidos tridimensionais. Já o segundo programa referido apresenta Recebido em: 18/01/2021

Aceito em: 24/02/2021 
Edição Especial: I SSAPEC - Simpósio Sul-Americano de Pesquisa em Ensino de Ciências

ISSN: 2595- $4520 \quad$ Vol. 4, n. 3. 2021

possibilidades de simulações e articulações entre álgebra e geometria, fator relevante para a aprendizagem de matemática, na visão de Tall (2008).

Tall (2008) aponta que nas aulas de matemática, de um modo geral, existe uma ênfase excessiva nos aspectos algébricos em detrimento dos geométricos, fator catalizador de dificuldades de aprendizagem. Assim, quando o professor faz uso de recursos direcionados, o âmbito visual é um movimento alternativo em relação ao ensino de matemática convencional, havendo possibilidade de melhoras em relação à aprendizagem.

Salienta-se a discrição desses movimentos, cuja concepção de uso não foi analisada, não se entendendo o uso de recursos tecnológicos digitais como a solução para os problemas da Educação. No entanto, cabe destacar que esses movimentos podem ser passos iniciais para o redimensionamento das crenças pedagógicas. $\mathrm{O}$ fato de o professor aventurar-se por um domínio desconhecido pode ser algo produtivo, sendo sugerida uma futura formação docente para que essas práticas sejam acompanhadas de um pensar pedagógico sobre as ações realizadas.

Mesmo de maneira forçada e artificial, os professores da rede pública viram-se obrigados a explorar a cultura digital, testando programas, recursos e oportunidades antes ausentes de seu cotidiano. As falas supracitadas demonstram o uso de softwares, mesmo com uma perceptível insegurança, a exploração dos recursos de vídeo e de realidade simulada. Lamenta-se o fato de essa mudança não ocorrer em uma circunstância de maior tranquilidade, garantindo ao professor um caminho menos acidentado na direção da inclusão de elementos da cultura digital nas suas aulas.

\section{CONSIDERAÇÕES FINAIS}

No momento da escrita deste artigo, a população mundial segue em isolamento domiciliar e as aulas no estado da rede pública de ensino do Rio Grande do Sul seguem o modelo remoto, com o uso de uma plataforma digital para a mediação das aulas. Não é possível conhecer os impactos futuros trazidos por essa circunstância, mas seguramente está sendo um período de dificuldades e oportunidades.

Dizer que os professores da rede pública estadual não estão preparados para o trabalho no ambiente digital não é algo novo, mas a existência da capacidade do Recebido em: 18/01/2021

Aceito em: 24/02/2021 
professor em se mobilizar e reinventar as suas práticas pode ser um ponto inicial para a formação docente para as tecnologias digitais. A inclusão da escola, sobretudo a pública, na cultura digital parece passar necessariamente pelos movimentos de formação docente, especialmente se ocorrer em uma conjuntura de maior tranquilidade.

O cenário digital oferece também oportunidades, muitas vezes desconhecidas, tanto em termos operacionais, quanto pedagógicos. Esse aspecto reforça mais a necessidade da formação docente, promovendo não apenas o uso, mas essencialmente o pensar sobre a docência no quadro da cultura digital. Tem-se indícios de que os professores de ciências e matemática da rede pública estadual estão abertos e dispostos à mudança, sendo que melhores resultados são obtidos quando existe apoio pedagógico para sustentar essas transformações.

A adequação do ensino de ciências e matemática às demandas do cidadão do século XXI parece ser algo necessário e urgente. As práticas adotadas durante o isolamento social trouxeram indícios de que isso é possível, mas ainda não está totalmente consolidado. Quiçá, tais práticas serão ampliadas e melhoradas a partir da reflexão sobre a ação, fomentando, assim, movimentos de inclusão da escola na cultura digital, a partir de uma mudança paradigmática relativa às formas como as aulas são concebidas e executadas.

Por último, salienta-se a possibilidade de que, futuramente, venha-se a enfrentar outras situações similares à vivida em 2020. Sugere-se um modelo emergencial previamente estabelecido para que, em situações imprevistas, o ensino seja prejudicado o mínimo possível, não apenas no sentido de manter o aluno com acesso ao conteúdo, mas de promover a aprendizagem de maneira efetiva, evitando a evasão e promovendo a aprendizagem, sobretudo na escola pública.

\section{REFERÊNCIAS}

BECKER, F. Construção do Conhecimento Matemático: natureza, transmissão e gênese. BOLEMA, v. 33, n. 65, dez. 2019. p. 963-987.

BOGDAN, R.; BIKLEN, S. Investigação Qualitativa em educação. Porto Editora: Porto, Portugal, 1994.

CURY, C. R. J. Educação escolar e pandemia. In: Pedagogia em Ação. Belo Horizonte, v. 13, n. 1, 2020.

FLORES, J. B. Letramento digital na formação superior do professor de matemática na modalidade a distância. 2013. 104 f. Dissertação (Mestrado em Educação) - Faculdade de Educação, Universidade de Caxias do Sul, Caxias do Sul, RS, 2013. 
FLICK, U. Uma introdução à pesquisa qualitativa. 2. ed. Porto Alegre: Bookman, 2004.

FRANÇA, A. C.; SOARES, M. (2015). Realidade virtual aplicada à educação: a era Matrix do processo de ensino e aprendizagem. XIII Congresso Internacional de Tecnologia na Educação. Anais: Recife, 2015.

FREIRE, P. A pedagogia do oprimido. 17. ed. Rio de Janeiro: Paz e Terra, 1987.

MAIA, C.; MATTAR, J. ABC da EaD. São Paulo: Pearson Prentice Hall, 2007.

MORAIS, A. D.; FAGUNDES, L. C. A inclusão digital da escola ou a inclusão da escola na cultura digital? Diálogo, Canoas, n. 19, p. 97-113, 2011.

MORAES, R.; GALIAZZI, M. do C. Análise textual discursiva. Ijuí: Unijuí, 2007.

MOREIRA, J. A.; HENRIQUES, S.; BARROS, D. Transitando de um ensino remoto emergencial para uma educação digital em rede, em tempos de pandemia. Dialogia, São Paulo, n. 34, p. 351-364, jan./abr. 2020.

PESCADOR, C. M.; FLORES, J. B. O Laptop Educacional na Escola: uma reflexão sobre inclusão digital. RENOTE (Revista Eletrônica de Tecnologia em Educação). Porto Alegre, v. 11, n. 1, p. 1-9, 2013.

SANTOS, B. S. A cruel pedagogia do vírus. (2020). Disponível em:

http://www.abennacional.org.br/site/wpcontent/uploads/2020/04/Livro_Boaventura.pdf.

Acesso em: 10 nov. 2020.

SARAIVA, K.; TRAVERSINI, C.; LOCKMANN, K. A educação em tempos de COVID-19: ensino remoto e exaustão docente. Práxis Educativa, Ponta Grossa, v. 15, p. 1-24, 2020.

SCHLEMMER, E.; MOREIRA, J. A. Por um novo conceito e paradigma de educação digital onlife. UFG, v. 20, n. 1, p. 2-35, 2020.

TALL, D. The Transition to Formal Thinking in Mathematics. Mathematics Education Research Journal, p. 5 - 24, 2008.

TARDIF, M.; LESSARD, C. O trabalho docente: elementos para uma teoria da docência como profissão de interações humanas. Tradução: João Batista Kreuch. 4. ed. Petrópolis, RJ: Vozes, 2008.

YIN, R. K. Estudo de Caso: planejamento e métodos. Tradução de Ana Thorell. 4. ed. Porto Alegre: Bookman, 2010. 